\title{
Оптические свойства метаморфной гибридной гетероструктуры вертикально излучающего лазера спектрального диапазона 1300 нм
}

\author{
(c) А.В. Бабичев ${ }^{1-3}$, Н.В. Крыжановская ${ }^{1}$, Э.И. Моисеев $^{1}$, А.Г. Гладышев ${ }^{2,3}$, Л.Я. Карачинский ${ }^{2-4}$, \\ И.И. Новиков ${ }^{2-4}$, С.А. Блохин ${ }^{4}$, М.А. Бобров ${ }^{4}$, Ю.М. Задиранов ${ }^{4}$, С.И. Трошков ${ }^{4}$, А.Ю. Егоров $2,3, \llbracket$ \\ ${ }^{1}$ Санкт-Петербургский национальный исследовательский Академический университет \\ Российской академии наук, \\ 194021 Санкт-Петербург, Россия \\ ${ }^{2}$ Санкт-Петербургский национальный исследовательский университет \\ информационных технологий, механики и оптики, \\ 197101 Санкт-Петербург, Россия \\ ${ }^{3}$ ООО «Коннектор Оптикс», \\ 194292 Санкт-Петербург, Россия \\ ${ }^{4}$ Физико-технический институт им. А.Ф. Иоффре \\ Российской академии наук, \\ 194021 Санкт-Петербург, Россия \\ ๑ E-mail: anton.egorov@connector-optics.com
}

(Получена 15 фревраля 2017 г. Принята к печати 22 февраля 2017 г.)

\begin{abstract}
Продемонстрирована возможность формирования гибридных метаморфных гетероструктур вертикально излучающих лазеров (ВИЛ) спектрального диапазона 1300 нм. Метаморфная полупроводниковая часть гетероструктуры с распределенным брэгговским отражателем на основе пары GaAs/AlGaAs и активной областью на основе квантовых ям InAlGaAs/InGaAs выращена методом молекулярно-пучковой эпитаксии на подложке $\mathrm{GaAs}(100)$. Верхнее диэлектрическое зеркало с распределенным брэгговским отражателем сформировано на основе пары $\mathrm{SiO}_{2} / \mathrm{Ta}_{2} \mathrm{O}_{5}$ методом магнетронного распыления. Проведено изучение спектров микрофотолюминесценции гетероструктур вертикально излучающих лазеров при комнатной температуре в диапазоне мощностей 0-70 мВт (длина волны оптической накачки составила 532 нм, диаметр сфокусированного пучка $\sim 1$ мкм). Наличие сверхлинейного хода зависимости интенсивности фотолюминесценции от мощности накачки наряду с заужением полуширины пиков фотолюминесценции и изменением модового состава могут быть обусловлены лазерной генерацией гетероструктуры вертикально излучающих лазеров. Полученные результаты свидетельствуют о возможности использования технологии метаморфного роста гетероструктур на подложках $\mathrm{GaAs}$ для создания вертикально излучающих лазеров спектрального диапазона 1300 нм.
\end{abstract}

DOI: 10.21883/FTP.2017.09.44879.8557

\section{1. Введение}

В настоящее время можно выделить две базовые технологии изготовления длинноволновых (ДВ) вертикально излучающих лазеров (ВИЛ). Первая состоит в создании монолитных полупроводниковых гетероструктур с распределенными брэгговскими отражателями (РБО) на основе пары материалов $\mathrm{GaAs} / \mathrm{AlGaAs}$, с упругонапряженными квантовыми ямами GaInAsN/GaAsN [1-7], GaInNAsSb/GaNAsSb [8-12] или квантовыми точками InAs/InGaAs [13-19]. Такие гетероструктуры выращиваются на подложках GaAs. Вторая технология основана на создании гибридных гетероструктур [20-24]. Основная отличительная особенность - сочетание полупроводниковой гетероструктуры, состоящей из РБО, и активной области с диэлектрическим РБО. В случае изготовления ДВ ВИЛ по второй технологии полупроводниковая гетероструктура обычно выращивается на подложке InP [21]. Для совмещения преимуществ ДВ ВИЛ на основе GaAs и ДВ ВИЛ на основе InP была предложена технология спекания пластин с гетероструктурами в различных системах материалов: РБО $\mathrm{AlGaAs} / \mathrm{GaAs}$ и активная область InGaAs/InP [20-22,25-30]. В этом случае предварительно на двух подложках из GaAs выра- щиваются РБО, затем на подложке из InP выращивается активная область с квантовыми ямами (КЯ). Гетероструктура, выращенная на подложке из InP, спекается с одним из РБО, затем подложка из InP удаляется, и далее проводится спекание полученной гетероструктуры со вторым РБО.

Альтернативный подход технологии спекания - использование метаморфных гетероструктур. Подход основан на выращивании на подложке, например из GaAs, переходного метаморфного слоя с отличной постоянной кристаллической решетки, например постоянной $\mathrm{InP}$, в процессе формирования которого сначала происходит релаксация упругих напряжений посредством образования дислокаций несоответствия, затем происходит постепенное уменьшение плотности дислокаций и в конечном результате формируется слой с новой постоянной кристаллической решетки и низкой плотностью дислокаций. Возможность успешной реализации приборов с использованием такого подхода была продемонстрирована рядом научных групп. Например, для выращивания квантовых точек с длиной волны излучения вблизи 1500 нм на подложках $\mathrm{GaAs}$ c метаморфным переходным слоем InGaAlAs [31,32], что в дальнейшем позволило реализовать эффективные ла- 
зеры с торцевым выводом излучения [33-35], для создания метаморфного туннельного перехода [36-39], метаморфных РБО на основе пары InGaAs/InAlAs [40], GaAs/AlAs [11,31,32,41-44], GaAs/AlGaAs-слоев [45-47], а также GaAs/InGaAs-буфера [48,49].

В данной работе приводятся результаты экспериментов по созданию и исследованию оптических свойств метаморфного гибридного вертикально излучающего лазера спектрального диапазона 1300 нм. Технология изготовления такого прибора основана на одновременном использовании двух подходов: формирования метаморфной гетероструктуры для реализации эффективного РБО и квантовых ям, излучающих на длине волны 1300 нм на одной полупроводниковой пластине из GaAs и гибридной технологии, путем комбинирования полупроводниковой и диэлектрической гетероструктур.

\section{2. Эксперимент}

Эпитаксиальная гетероструктура гибридного метаморфного ВИЛ с оптической накачкой изготовлена методом молекулярно-пучковой эпитаксии (МПЭ) на промышленной установке Riber MBE49 компанией ООО „Коннектор Оптикс“. На подложке $\mathrm{GaAs}(100)$ выращен РБО, состоящий из 33 пар чередующихся слоев GaAs и $\mathrm{Al}_{0.92} \mathrm{Ga}_{0.18} \mathrm{As}$ с толщинами 99.6 и $114.0 \mathrm{Hм}$ соответственно, с последующим формированием метаморфного буферного слоя толщиной $500 \mathrm{нм}$, обеспечивающий переход от постоянной решетки GaAs к постоянной решетки $\operatorname{In}_{0.26} \mathrm{Ga}_{0.74} \mathrm{As}$. Активная область лазера состояла из 6 квантовых ям (КЯ) $\operatorname{In}_{0.43} \mathrm{Ga}_{0.57} \mathrm{As}$ толщиной 5.9 нм, расположенных в слое $\operatorname{In}_{0.26} \mathrm{Ga}_{0.74} \mathrm{As}$, ограниченных со стороны подложки и поверхности дополнительными барьерными слоями $\operatorname{In}_{0.26} \mathrm{Al}_{0.74} \mathrm{As}$. Bepxний слой $\mathrm{In}_{0.26} \mathrm{Al}_{0.74} \mathrm{As}$ прикрывался слоем $\mathrm{In}_{0.26} \mathrm{Ga}_{0.74} \mathrm{As}$ толщиной 5 нм для предотвращения окисления при контакте с воздухом. Метаморфный буферный слой и активная область формируют нелегированный оптиче-

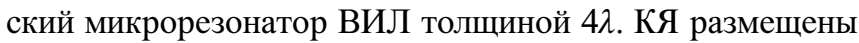
в пучностях стоячей волны для обеспечения высокого фактора перекрытия профиля распределения стоячей волны с активной областью. Толщина и состав КЯ были выбраны для получения эффективной излучательной рекомбинации вблизи резонансной длины волны микрорезонатора. Температура роста основной части гетероструктуры составляла $480-500^{\circ} \mathrm{C}$, тогда как КЯ формировались при пониженной температуре $430^{\circ} \mathrm{C}$.

С целью реализации оптической накачки использована гибридная геометрия вертикального оптического микрорезонатора с верхним диэлектрическим РБО. Выбор материалов диэлектрических слоев верхнего РБО обусловлен обеспечением требований прозрачности слоев на длине волны лазера накачки, низкой шероховатостью интерфейсов гетерограниц РБО и малой оптической неоднородностью слоев РБО. Несмотря на успешное применение $\mathrm{SiO}_{2} / \mathrm{TiO}_{2}$ РБО в гибридных инжекционных ВИЛ спектрального диапазона 850 нм [50], попытки использования $\mathrm{TiO}_{2}$ для данного спектрального диапазона не привели к удовлетворительному результату. Данные оптической эллипсометрии и электромеханического профилирования показали, что поликристалличность слоев $\mathrm{TiO}_{2}$ приводит к сильной шероховатости гетерограниц и флуктуациям показателя преломления слоев, и, как следствие, к нежелательному рассеянию света. В свою очередь продемонстрирована шероховатость поверхности $\mathrm{Ta}_{2} \mathrm{O}_{5}$ на уровне атомных ступеней полупроводниковой подложки GaAs, оптическая неоднородность материала слоев находится на уровне погрешности измерений. В результате в качестве верхнего выводного зеркала использовался диэлектрический РБО на основе пар $\lambda / 4$ слоев $\mathrm{SiO}_{2}$ и $\mathrm{Ta}_{2} \mathrm{O}_{5}$. Слои сформированы реактивным магнетронным распылением кварцевой и танталовой мишени на переменном токе в атмосфере $\mathrm{O}_{2}$ при температуре $70^{\circ} \mathrm{C}$. Коэффициенты экстинкции выбранных слоев $\mathrm{SiO}_{2}$ и $\mathrm{Ta}_{2} \mathrm{O}_{5}$ в спектральном диапазоне 1300 нм равны нулю, а показатели преломления равны 1.47 и 2.03 соответственно.

Для измерения зависимости интенсивности люминесценции от мощности накачки использовался лазер YAG: $\mathrm{Nd}$, работающий в непрерывном режиме на второй гармонике $(\lambda=532 \mathrm{нм})$. Измерения проводились при комнатной температуре. Объектив Mitutoyo MPlan $\times 100$ с пьезоподвижками использовался для накачки и сбора сигнала. Лазерный луч фокусировался в пятно диаметром 1 мкм. Для детектирования сигнала использовался монохроматор MS5204i (Sol Instruments) и ПЗС-камера InGaAs iDUS (Andor).

\section{3. Результаты и их обсуждение}

Изображение сканирующей электронной микроскопии (СЭМ) сформированного гибридного ВИЛ представлено на рис. 1. На рис. 2, $a$ представлены спектры отражения метаморфной гибридной гетероструктуры ВИЛ с

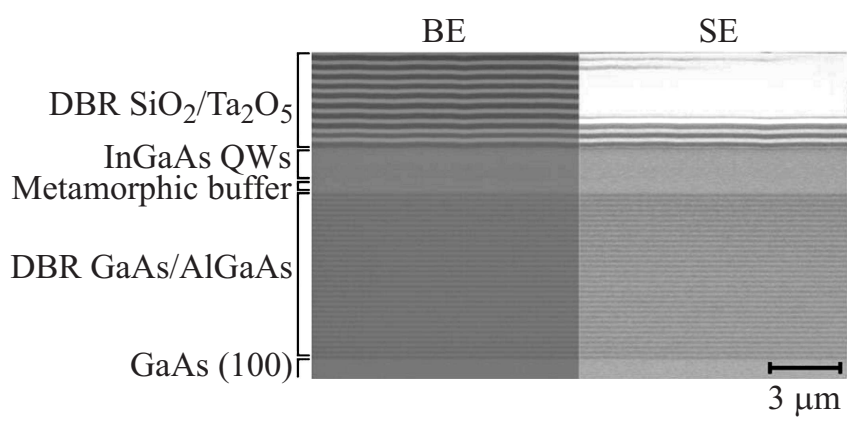

Рис. 1. Изображение сканирующей электронной микроскопии (СЭМ) скола метаморфной гибридной гетероструктуры ВИЛ с 10 парами $\mathrm{SiO}_{2} / \mathrm{Ta}_{2} \mathrm{O}_{5}$, формирующими диэлектрический РБО. ВЕ - режим отраженных электронов, SE - режим вторичных электронов. Светлый контраст соответствует слоям InGaAs или $\mathrm{Ta}_{2} \mathrm{O}_{5}$, а темный - слоям $\mathrm{Al}(\mathrm{In}) \mathrm{GaAs}$ или $\mathrm{SiO}_{2}$. Обозначение InGaAs QWs отражает расположение активной области ВИЛ, включающей данные QWs. 

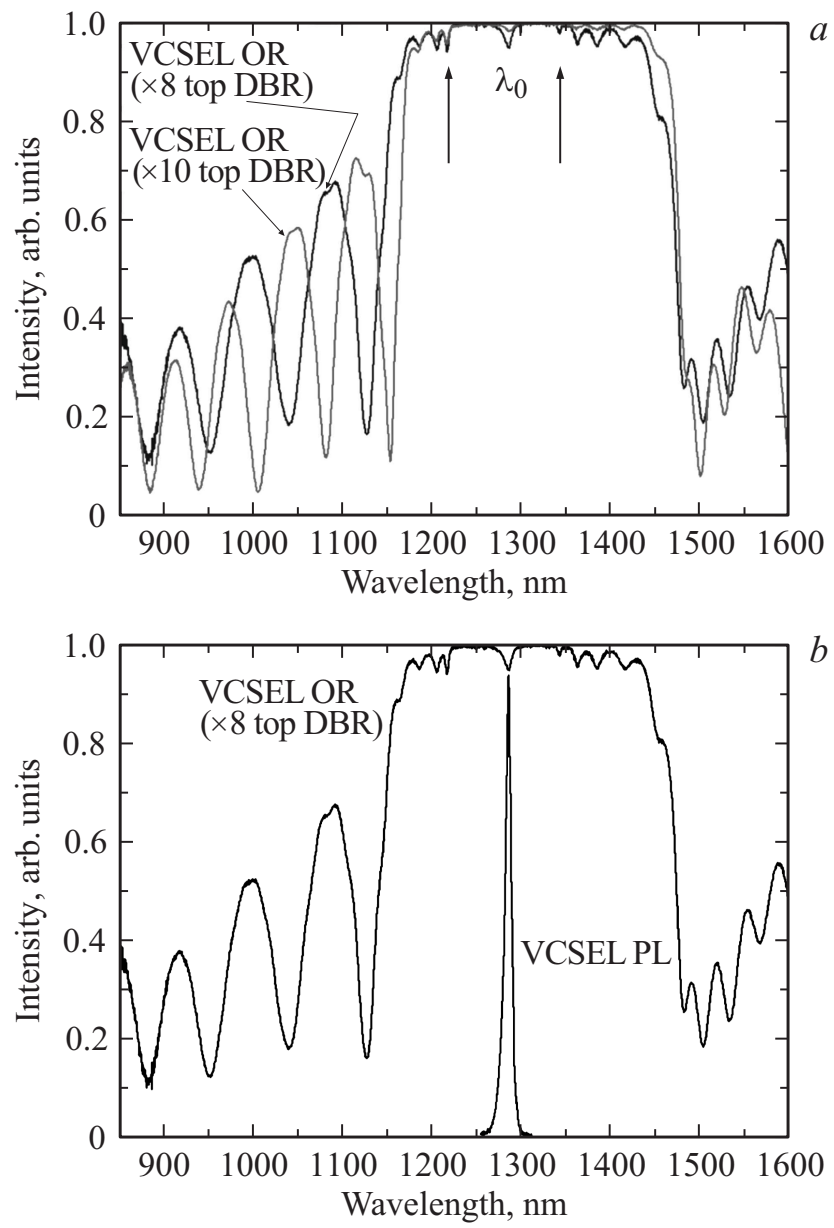

Pис. 2. Спектры оптического отражения (VCSEL OR) и фотолюминесценции (VCSEL PL) метаморфной гибридной гетероструктуры ВИЛ с диэлектрическим РБО на основе 8 пар $\mathrm{SiO}_{2} / \mathrm{Ta}_{2} \mathrm{O}_{5}$.

различным числом пар слоев $\mathrm{SiO}_{2} / \mathrm{Ta}_{2} \mathrm{O}_{5}$, формирующих диэлектрический РБО. Благодаря большому контрасту показателей преломления слоев $\mathrm{SiO}_{2} / \mathrm{Ta}_{2} \mathrm{O}_{5}$ диэлектрическое РБО имеет в 2-3 раза большую полосу высокого отражения (так называемую stop-band) по сравнению с полупроводниковым РБО, поэтому в спектрах оптического отражения метаморфной гибридной гетероструктуры ВИЛ наряду с основным резонансом $\lambda_{0}$ присутствуют и локальные минимумы, связанные с толщинными осцилляциями полупроводникового РБО. По мере увеличения количества пар в диэлектрическом РБО все особенности в полосе высокого отражения сохраняются, а глубина локального минимума $\lambda_{0}$ заметно уменьшается. Спектры оптического отражения (VCSEL OR) и фотолюминесценции (VCSEL PL) метаморфной гибридной гетероструктуры ВИЛ представлены на рис. 2, $b$. Максимум спектра ФЛ гибридной гетероструктуры ВИЛ при малой плотности возбуждающего излучения соответствует спектральному положению локального минимума $\lambda_{0}$. Таким образом, в результате напыления диэлектрического РБО удается сформировать вертикальный оптический микрорезонатор с резонансной длиной волны вблизи 1297 нм. Следует отметить, что спектральное положение резонансной длины волны микрорезонатора совпадает с максимумом интенсивности спектра ФЛ тестовой метаморфной полупроводниковой гетероструктуры с квантовыми ямами InGaAs. C целью достижения компромисса между высокими потерями на выход излучения и низкой пороговой мощностью оптической накачки для дальнейших экспериментов была выбрана гетероструктура метаморфного гибридного ВИЛ с диэлектрическим РБО на основе 8 пар слоев $\mathrm{SiO}_{2} / \mathrm{Ta}_{2} \mathrm{O}_{5}$.

Спектры оптического излучения метаморфной гибридной гетероструктуры ВИЛ, измеренные при различных мощностях оптической накачки, представлены на

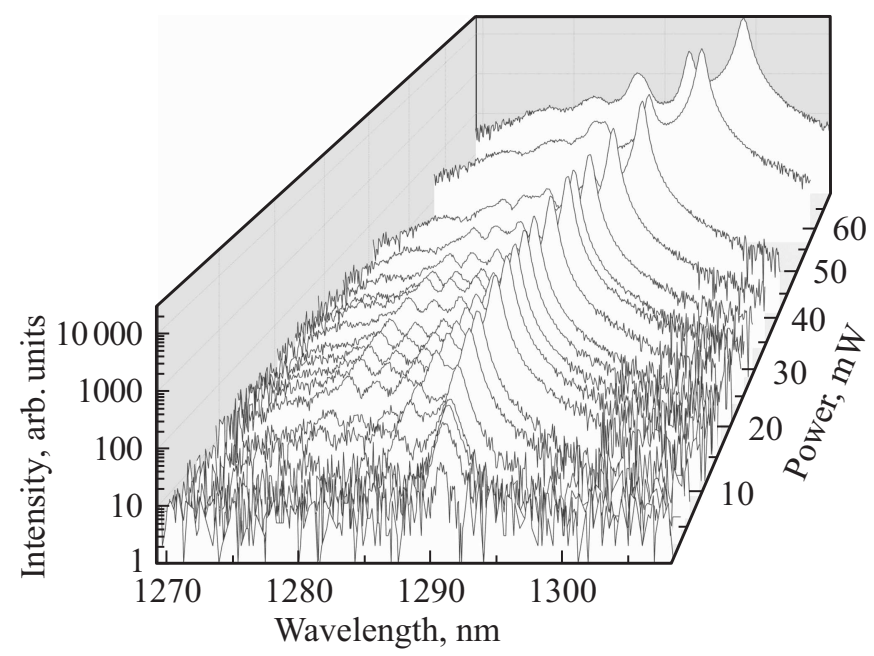

Рис. 3. Спектры стимулированного излучения гетероструктуры метаморфного гибридного ВИЛ с диэлектрическим РБО на основе 8 пар $\mathrm{SiO}_{2} / \mathrm{Ta}_{2} \mathrm{O}_{5}$ при различной мощности оптической накачки.

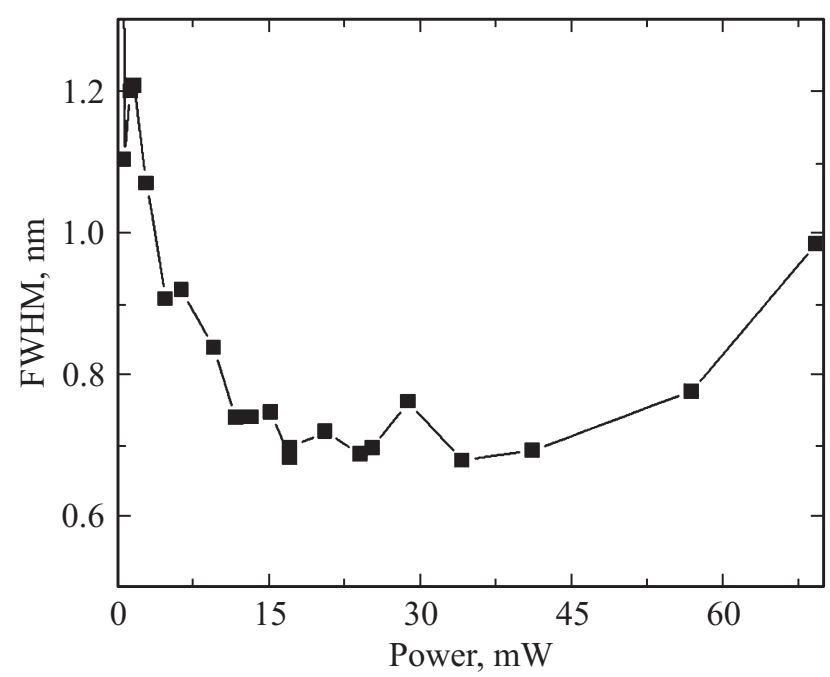

Рис. 4. Зависимость ширины на полувысоте для основного пика гетероструктуры метаморфного гибридного ВИЛ с диэлектрическим РБО на основе 8 пар $\mathrm{SiO}_{2} / \mathrm{Ta}_{2} \mathrm{O}_{5}$ от мощности оптического возбуждения. 


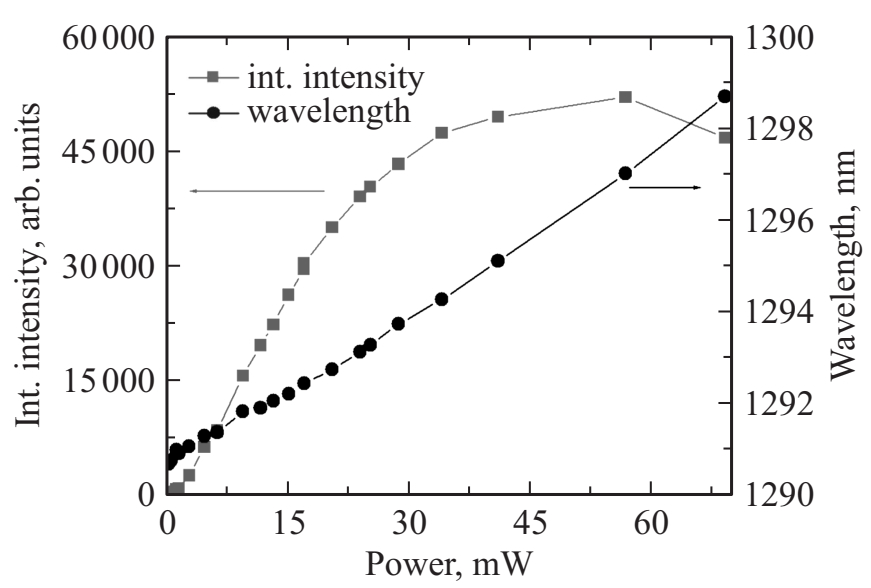

Pис. 5. Зависимости спектрального положения максимума фотолюминесценции и интегральной интенсивности сигнала фотолюминесценции метаморфной гибридной гетероструктуры ВИЛ с диэлектрическим РБО на основе 8 пар $\mathrm{SiO}_{2} / \mathrm{Ta}_{2} \mathrm{O}_{5}$ при различной мощности возбуждающего излучения.

рис. 3. При малых мощностях возбуждающего излучения в спектрах наблюдается только одна основная мода. С ростом мощности оптической накачки наблюдается разгорание более коротковолновых пиков, сдвиг всех пиков в длинноволновую сторону и увеличение спектрального расстояния между двумя наиболее интенсивными пиками. Из рис. 4 видно, что с повышением плотности накачки наблюдается также сильное заужение спектральных линий до 0.7 нм (ограничено разрешающей способностью использованного оборудования).

Зависимость интегральной интенсивности микро-ФЛ от мощности накачки приведена на рис. 5. Зависимость демонстрирует сверхлинейный ход с областью насыщения при мощности оптической накачки, превышающей 40 мВт. Насыщение, скорее всего, обусловлено разогревом гетероструктуры при больших плотностях накачки. Согласно зависимости длины волны основного пика ФЛ от мощности оптической накачки (рис. 5), сдвиг основной моды достигает 8 нм, что свидетельствует о существенном разогреве ВИЛ. Оценка температуры разогрева гетероструктуры под воздействием оптической накачки, используя температурный коэффициент $0.056 \mathrm{нм} / \mathrm{K}$ [51], показывает, что максимальная рабочая температура созданного ВИЛ может достигать величины $120^{\circ} \mathrm{C}$, что коррелирует с типичными значениями предельной внутренней температуры инжекционных ВИЛ. Сверхлинейное разгорание ФЛ, пороговое изменение характера зависимости интегральной интенсивности сигнала ФЛ при значении мощности возбуждающего излучения 2 мВт наряду с заужением ширины линии основного пика и модификацией модового состава при увеличении мощности возбуждающего излучения могут свидетельствовать о формировании поперечного эффективного волновода (эффект тепловой линзы) и возникновении лазерной генерации [52].

\section{4. Заключение}

Методом молекулярно-пучковой эпитаксии (МПЭ) и магнетронного распыления реализован гибридный вертикально излучающий лазер (ВИЛ). Пороговое значение мощности возбуждающего излучения, при котором начинается сверхлинейное увеличение интенсивности выходящего излучения, соответствует значению 2 мВт. При малых мощностях возбуждающего излучения в спектре наблюдается только одна основная мода. По мере увеличения мощности накачки в спектре генерации возникают дополнительные лазерные моды. Увеличение мощности возбуждающего излучения приводит к постепенному разогреву гетероструктуры и сдвигу спектрального положения основной моды на 8 нм при максимальном значении мощности накачки. Соответствующее оценочное значение температуры гетероструктуры составляет не менее $120^{\circ} \mathrm{C}$. Наличие сверхлинейного хода зависимости интенсивности ФЛ от мощности накачки наряду с заужением полуширины пиков ФЛ и изменением модового состава могут быть обусловлены наличием лазерной генерации.

Работа выполнена при частичной поддержке Министерства образования и науки, Российского фонда фундаментальных исследований, проекты 14-29-08273 офи-м и 16-29-03127 офи-м. Авторы также выражают благодарность П.Н. Брункову за исследования методом электромеханического профилирования (AFM) и В.С. Левицкому за исследования методом оптической эллипсометрии.

\section{Список литературы}

[1] M. Reinhardt, M. Fischer, M. Kamp, J. Hofmann, A. Forchel. IEEE Phot. Techn. Lett., 12 (3), 239 (2000).

[2] M. Fischer, M. Reinhardt, A. Forchel. IEEE Phot. Techn. Lett., 12 (10), 1313 (2000).

[3] M. Larson, M. Kondow, T. Kitatani, Y. Yazawa, M. Okai. Electron. Lett., 33, 959 (1997).

[4] C. Ellmers, F. Höhnsdorf, J. Koch, C. Agert, S. Leu, D. Karaiskaj, M. Hofmann, W. Stolz, W. Rühle. Appl. Phys. Lett., 74, 2271 (1999).

[5] T. Takeuchi, Y.L. Chang, M. Leary, A. Tandon, H.C. Luan, D. Bour, S. Corzine, R. Twist, M. Tan. Electron. Lett., 38 (23), 1438 (2002).

[6] F. Mederer, I. Ecker, R. Michalzik, G. Steinle, H. Riechert, B. Lunitz, J. Moisel, D. Wiedenmann. In: 52nd IEEE Electron. Compon. Techn. Conf. Proceedings (San Diego, California USA, 2002) p. 5.

[7] M. Baranowski, R. Kudrawiec, J. Misiewicz, M. Hammar. Appl. Phys. A, 118 (2), 479 (2015).

[8] M.A. Wistey, S.R. Bank, H.P. Bae, H.B. Yuen, E.R. Pickett, L.L. Goddard, J.S. Harris. Electron. Lett., 42 (5), 1 (2006).

[9] S.R. Bank, L.L. Goddard, M.A. Wistey, H.B. Yuen, J.S. Harris. IEEE J. Select. Top. Quant. Electron., 11 (5), 1089 (2005).

[10] T. Sarmiento, H.P. Bae, T.D. O’sullivan, J.S. Harris. Electron. Lett., 45 (19), 978 (2009).

[11] V.M. Korpijärvi, E.L. Kantola, T. Leinonen, R. Isoaho, M. Guina. IEEE J. Select. Top. Quant. Electron., 21 (6), 480 (2015). 
[12] J.S. Harris, H. Bae, T. Sarmiento. In: VCSELs Fundamentals, Technology and Applications of Vertical-Cavity SurfaceEmitting Lasers, ed. by R. Michalzik (Heidelberg-N.Y.Dordrecht-London, Springer, 2013).

[13] H.C. Yu, J.S. Wang, Y.K. Su, S.J. Chang, F.I. Lai, Y.H. Chang, H.C. Kuo, C.P. Sung, H.P.D. Yang, K.F. Lin, J.M. Wang, J.Y. Chi, R.S. Hsiao, J.M. Wang. IEEE Photonics Technol. Lett., 18 (2), 418 (2006).

[14] K. Akahane, N. Yamamoto, T. Kawanishi. IEEE Phot. Techn. Lett., 22 (2), 103 (2010).

[15] A.R. Kovsh, N.A. Maleev, A.E. Zhukov, S.S. Mikhrin, A.P. Vasil'ev, E.A. Semenova, Yu.M. Shernyakov, M.V. Maximov, D.A. Livshits, V.M. Ustinov, N.N. Ledentsov, D. Bimberg, Zh.I. Alferov. J. Cryst. Growth, 251 (1), 729 (2003).

[16] N.V. Kryzhanovskaya, E.I. Moiseev, Y.V. Kudashova, F.I. Zubov, A.A. Lipovskii, M.M. Kulagina, S.I. Troshkov, Yu.M. Zadiranov, D.A. Livshits, M.V. Maximov, A.E. Zhukov. Electron. Lett., 51 (17), 1354 (2015).

[17] K. Akahane, N. Yamamoto, T. Umezawa, A. Kanno, T. Kawanishi. Jpn. J. Appl. Phys., 53 (4S), 04EG02 (2014).

[18] D. Gready, G. Eisenstein, V. Ivanov, C. Gilfert, F. Schnabel, A. Rippien, J.P. Reithmaier, C. Bornholdt. IEEE Photonics Technol. Lett., 26 (1), 11 (2014).

[19] H. Huang, K. Schires, L.C. Lin, C.Y. Chen, D. Arsenijević, D. Bimberg, F.Y. Lin, F. Grillot. CLEO: Science and Innovations, San Jose, CA, 2016, OSA Technical Digest (2016) [(Optical Society of America, Washington, DC, 2016) p. STh4L-6].

[20] S. Paul, C. Gierl, J. Cesar, Q.T. Le, M. Malekizandi, B. Kögel, C. Neumeyr, M. Ortsiefer, F. Küppers. IEEE J. Select. Top. Quant. Electron., 21 (6), 436 (2015).

[21] E. Kapon, A. Sirbu. Nature Photonics, 3 (1), 27 (2009).

[22] H.K. Sahoo, T. Ansbæk, L. Ottaviano, E.S. Semenova, O. Hansen, K. Yvind. Proc. SPIE 9760, MOEMS and Miniaturized Systems $X V$ (San Francisco, CA, United States, 2016) p. $97600 \mathrm{X}$.

[23] C. Levallois, A. Le Corre, S. Loualiche, O. Dehaese, H. Folliot, C. Paranthoen, F. Thoumyre, C. Labbé. J. Appl. Phys., 98 (4), 043107 (2005).

[24] H.W. Song, W.S. Han, J.H. Kim, O.K. Kwon, Y.G. Ju, J.H. Lee, S.H. KoParkm, S.G. Kang. Electron. Lett., 40, 868 (2004).

[25] E.P. Haglund, S. Kumari, P. Westbergh, J.S. Gustavsson, G. Roelkens, R. Baets, A. Larsson. Opt. Express, 23 (26), 33634 (2015).

[26] J. Ferrara, W. Yang, L. Zhu, P. Qiao, C.J. Chang-Hasnain. Opt. Express, 23 (3), 2512 (2015).

[27] A. Caliman, A. Sirbu, V. Iakovlev, A. Mereuta, P. Wolf, D. Bimberg, E. Kapon. Optical Fiber Communication Conference, Anaheim, CA, 2016, OSA Technical Digest [(Optical Society of America, Washington, DC, 2016) p. Tu3D-1].

[28] R.M. von Wurtemberg, X. Yu, J. Berggren, M. Hammar. IET Optoelectron., 3 (2), 112 (2009).

[29] A. Mereuta, A. Sirbu, A. Caliman, G. Suruceanu, V. Iakovlev, Z. Mickovic, E. Kapon. J. Cryst. Growth, 414, 210 (2015).

[30] A.V. Babichev, L.Y. Karachinsky, I.I. Novikov, A.G. Gladyshev, S. Mikhailov, V. Iakovlev, A. Sirbu, G. Stepniak, L. Chorchos, J. Turkiewicz, M. Agustin, N.N. Ledentsov, A.Y. Egorov. Proc. SPIE 9766, Vertical-Cavity Surface-Emitting Lasers XXI (San Francisco, CA, United States, 2017) p. 10122-7].

[31] И.И. Новиков, М.В. Максимов, Ю.М. Шерняков, Н.Ю. Гордеев, А.Р. Ковш, А.Е. Жуков, С.С. Михрин, Н.А. Мале- ев, А.П. Васильев, В.М. Устинов, Ж.И. Алферов. ФТП, 37 (10), 1270 (2003).

[32] N.N. Ledentsov, A.R. Kovsh, A.E. Zhukov, N.A. Maleev, S.S. Mikhrin, A.P. Vasil'ev, E.S. Semenova, M.V. Maximov, Yu.M. Shernyakov, N.V. Kryzhanovskaya, V.M. Ustinov, D. Bimberg. Electron. Lett. 39 (15), 1126 (2003).

[33] T. Kettler, L.Y. Karachinsky, N.N. Ledentsov, V.A. Shchukin, G. Fiol, M. Kuntz, A. Lochmann, O. Schulz, L. Reissmann, K. Posilovic, D. Bimberg, I.I. Novikov, Yu.M. Shernyakov, N.Yu. Gordeev, M.V. Maximov, N.V. Kryzhanovskaya, A.E. Zhukov, E.S. Semenova, A.P. Vasil'ev, V.M. Ustinov, A.R. Kovsh. Appl. Phys. Lett., 89 (4), 041113 (2006).

[34] L.Y. Karachinsky, T. Kettler, I.I. Novikov, Y.M. Shernyakov, N.Y. Gordeev, M.V. Maximov, N.V. Kryzhanovskaya, A.E. Zhukov, E.S. Semenova, A.P. Vasil'ev, V.M. Ustinov, G. Fiol, M. Kuntz, A. Lochmann, O. Schulz, L. Reissmann, K. Posilovic, A.R. Kovsh, S.S. Mikhrin, V.A. Shchukin, N.N. Ledentsov, D. Bimberg. Semicond. Sci. Technol., 21 (5), 691 (2006).

[35] N.N. Ledentsov, V.A. Shchukin, T. Kettler, K. Posilovic, D. Bimberg, L.Y. Karachinsky, A.E. Zhukov. J. Cryst. Growth, 301, 914 (2007).

[36] I. García, J.F. Geisz, R.M. France, J. Kang, S.H. Wei, M. Ochoa, D.J. Friedman. J. Appl. Phys., 116 (7), 074508 (2014).

[37] J. Boucart, R. Pathak, D. Zhang, M. Beaudoin, P. Kner, D. Sun, R.J. Stone, R.F. Nabiev, W. Yuen. IEEE Photonics Technol. Lett., 15 (9), 1186 (2003).

[38] P. Kner, T. Kageyama, J. Boucart, R. Stone, D. Sun, R.F. Nabiev, R. Pathak, W. Yuen. IEEE Phot. Technol. Lett., 15 (9), 1183 (2003).

[39] D. Sun, W. Fan, P. Kner, J. Boucart, T. Kageyama, R. Pathak, D. Zhang, W. Yuen. IEEE Phot. Technol. Lett., 15 (12), 1677 (2003).

[40] А.Ю. Егоров, Л.Я. Карачинский, И.И. Новиков, А.В. Бабичев, Т.Н. Березовская, В.Н. Неведомский. ФТП, 49 (10), 1434 (2015).

[41] J.P. Tourrenc, S. Bouchoule, A. Khadour, J.C. Harmand, A. Miard, J. Decobert, N. Lagay, X. Lafosse, I. Sagnes, L. Leroy, J.L. Oudar. Optical Quant. Electron., 40 (2-4), 155 (2008).

[42] J.P. Tourrenc, S. Bouchoule, A. Khadour, J. Decobert, A. Miard, J.C. Harmand, J.L. Oudar. Electron. Lett., 43 (14), 1 (2007).

[43] J. Boucart, C. Starck, F. Gaborit, A. Plais, N. Bouche, E. Derouin, L. Goldstein, C. Fortin, D. Carpentier, P. Salet, F. Brillouet, J. Jacquet. IEEE Phot. Techn. Lett., 11 (6), 629 (1999).

[44] J. Cheng, C.L. Shieh, X. Huang, G. Liu, M.V.R. Murty, C.C. Lin, D.X. Xu. IEEE Phot. Techn. Lett., 17 (1), 7 (2005).

[45] Y. Ohiso, R. Iga. Thin Sol. Films, 542, 317 (2013).

[46] L. Goldstein, C. Fortin, C. Starck, A. Plais, J. Jacquet, J. Boucart, A. Rocher, D. Carperntier, C. Poussou. Electron. Lett., 34 (3), 268 (1998).

[47] J. Boucart, C. Starck, A. Plais, E. Derouin, C. Fortin, F. Gaborit, A. Pinquier, L. Goldstein, D. Carperntier, J. Jacquet. Electron. Lett., 34 (22), 2133 (1998).

[48] D. Wu, H. Wang, B. Wu, H. Ni, S. Huang, Y. Xiong, P. Wang, Q. Han, Z. Niu, I. Tangring, S. M. Wang. Electron. Lett., 44 (7), 1 (2008).

[49] I. Tangring, S. Wang, M. Sadeghi, A. Larsson. Electron. Lett., 42 (12), 691 (2006). 
[50] Н.А. Малеев, А.Г. Кузьменков, М.М. Кулагина, Ю.М. Задиранов, А.П. Васильев, С.А. Блохин, А.С. Шуленков, С.И. Трошков, А.Г. Гладышев, А.М. Надточий, М.М. Павлов. ФТП, 47 (7), 985 (2013).

[51] S.K. Mandre, W. Elsäßer, I. Fischer, M. Peeters, G. Verschaffelt. Appl. Phys. Lett., 89 (15), 151106 (2006).

[52] С.А. Блохин, Н.В. Крыжановская, Э.И. Моисеев, М.А. Бобров, А.Г. Кузьменков, А.А. Блохин, А.П. Васильев, И.О. Карповский, Ю.М. Задиранов, С.И. Трошков, В.Н. Неведомский, Е.В. Никитина, Н.А. Малеев, В.М. Устинов. Письма в ЖТФ, 42 (19), 70 (2016).

Редактор Г.А. Оганесян

\section{Optical properties of metamorphic hybrid $1300 \mathrm{~nm}$ spectral band VCSEL heterostucture}

A.V. Babichev ${ }^{1-3}$, N.V. Kryzhanovskaya ${ }^{1}$, E.I. Moiseev ${ }^{1}$, A.G. Gladyshev, ${ }^{2,3}$,

L.Ya. Karachinsky ${ }^{2-4}$, I.I. Novikov ${ }^{2-4}$, S.A. Blokhin ${ }^{4}$, M.A. Bobrov ${ }^{4}$, Yu.M. Zadiranov ${ }^{4}$, S.I. Troshkov ${ }^{4}$, A.Yu. Egorov ${ }^{2,3}$

${ }^{1}$ Saint Petersburg Academic University, 194021 St. Petersburg, Russia

${ }^{2}$ Connector Optics LLC,

194292 St. Petersburg, Russia

${ }^{3}$ ITMO University,

197101 St. Petersburg, Russia

${ }^{4}$ Ioffe Institute,

194021 St. Petersburg, Russia

Abstract The ability to create metamorphic hybrid heterostructure of $1300 \mathrm{~nm}$ spectral band VCSEL is demonstrated. Metamorphic semiconductor part of heterostructure with $\mathrm{GaAs} / \mathrm{AlGaAs}$ DBR and InAlGaAs/InGaAs QW active region has been grown by molecular beam epitaxy (MBE) on $\operatorname{GaAs}(100)$. Top dielectric $\mathrm{SiO}_{2} / \mathrm{Ta}_{2} \mathrm{O}_{5}$ DBR is made by the magnetron sputtering method. VCSEL has been studied under optical pumping $(\lambda=532 \mathrm{~nm}$, diameter of the focused laser beam of $\sim 1 \mu \mathrm{m}$ ) by using micro-PL setup in the range of optical pump power $0-70 \mathrm{~mW}$ at room temperature. Presence of the superlinear PL intensity growth having threshold-like dependence of PL integral intensity together with the PL peaks narrowing and mode composition modification with the pumping density increasing could be attributed to lasing behavior of the structure. Obtained results indicate the opportunity to use metamorphic growth on GaAs substrates for the $1300 \mathrm{~nm}$ range VCSEL manufacturing. 